Proceedings

\title{
Solutions in Drinking Water Networks. Lifehygenet Project $^{+}$
}

\author{
Daniel Álvarez Díaz, Manuel Alejandro Fernández Hernández and Sergio García Morán * \\ Fundación Prodintec, 33203 Gijón, Spain; dad@prodintec.com (D.Á.D.); mfh@prodintec.com (M.A.F.H.) \\ * Correspondence: sgm@prodintec.com; Tel.: +34-984-390-060 \\ + Presented at the 2nd International Research Conference on Sustainable Energy, Engineering, Materials and \\ Environment (IRCSEEME), Mieres, Spain, 25-27 July 2018.
}

Published: 13 November 2018

\begin{abstract}
The main aim of this project is focused on designing, developing and installing a modular system to generate electricity, using kinetic and potential energy currently wasted in distributions and water supplies networks.
\end{abstract}

Keywords: electricity; water supply network; modular generator; hydraulic; water abduction

\section{Introduction}

Water distribution networks have, in general, intake and delivery points located at different heights. In this sense, when the gap between the catchment reservoir and the storage tank is high, it is necessary to have a device to reduce the pressure in the pipeline to prevent the rupture. The system most used is a break pressure tank. In the tank, the pressure of the fluid turns to atmospheric pressure, dissipating all the potential and kinetic energy of the water flow, which is not used.

In order to take advantage of this dissipated energy, a modular system for the generation of electrical energy has been developed, located on the break pressure tanks that are in the mentioned networks, and which is located parallel to this existing tanks. This system can generate energy from a present resource that is not used, minimizing the associated infrastructure works, conceiving the device as modular and pre-assembled in the factory. In addition, the parallel situation of the system, allows guaranteeing all the time the quality of the supply, because if it's necessary, it is possible to conduce the flow through the traditional pressure dissipation system.

These developments are part of the activities of the LifeHyGENet project "HYDRAULIC COGENERATION SYSTEM IN WATER ABDUCTION AND DISTRIBUTION NETWORK", a project funded by the European Commission in the LIFE call, with code LIFE12 ENV/ES/000695 and whose consortium is formed by: F. Prodintec, Ingemas, Servoship, Faen and Mieres City Council. The pilot plant is located in the water network of the Municipality of Mieres, Asturias.

\section{Operating Principle}

There are different types of water supply networks that can be used either for human consumption or for other uses such as industrial or agricultural, which are usually conditioned by the geography of the area. This geographical conditioning motivates the existence of different levels for the reservoirs and the consumption points. According to the laws of physics, when a fluid circulates through a closed pipeline and the reservoir or collection tank level is higher than the fluid discharge level, it circulates by gravity, showing an increasing pressure with the descent of height. In the extreme case, when the fluid reach the lower level of the pipeline and it is stopped, the pressure reaches a maximum value, corresponding to the hydrostatic pressure (Obviating the transitory 
overpressure caused by the water hammer associated with fast close maneuver). A general scheme is shown below (Figure 1).

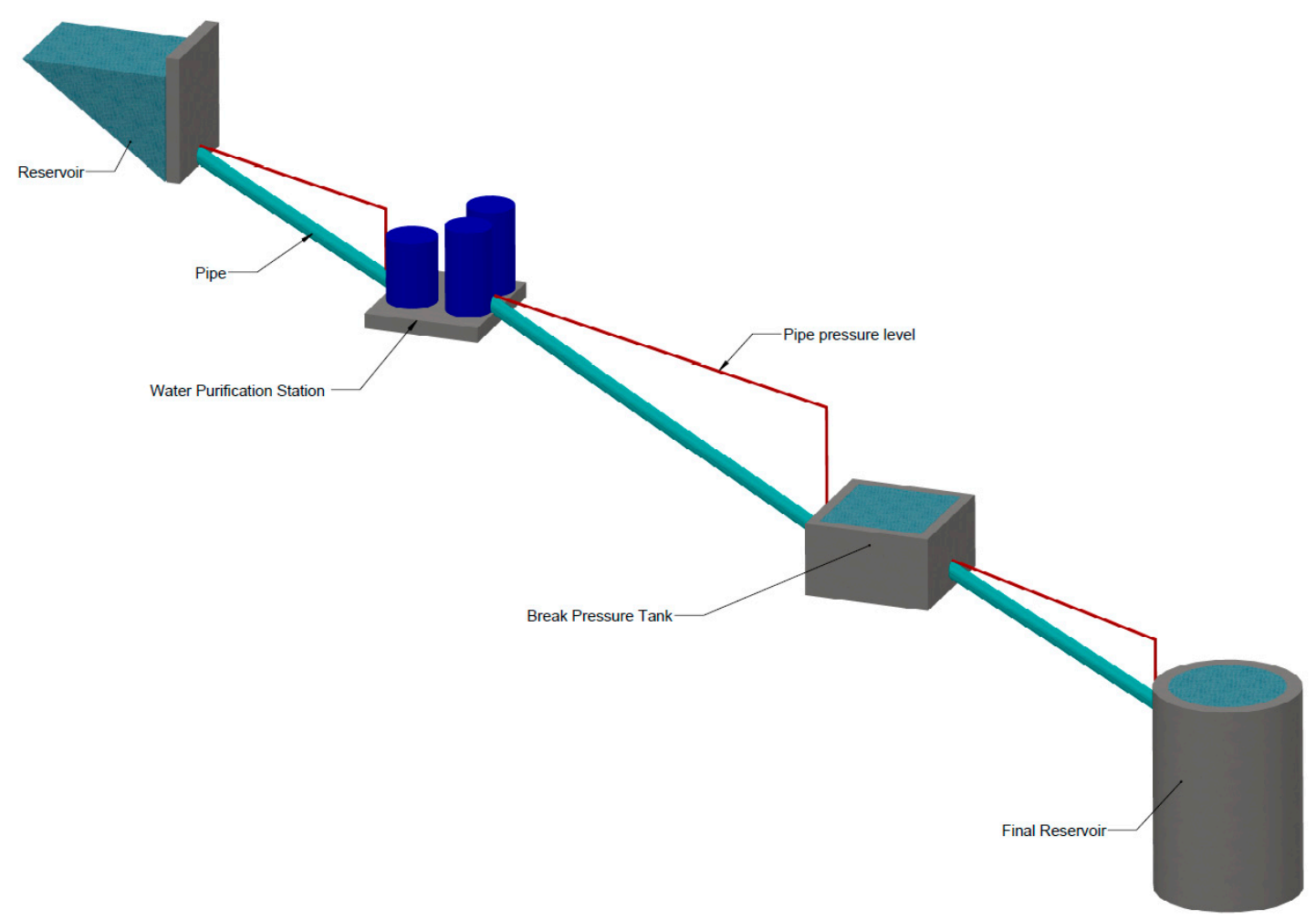

Figure 1. General scheme.

This accumulated pressure means that the water pipes that present these characteristics must be designed to provide different points of load rupture or pressure relief, as shown in Figure 1 . The energy of the fluid is dissipated into the environment. In order to use this potential energy, a new system was developed to allow the use of water flow energy, maintaining the existing infrastructure.

The device consists, in conceptually way, in the installation of a turbine in by-pass to the existing load breaking device as shown in Figure 2. In this way, it is possible that the water runs through the device generating electric energy or, in case of the device is stopped; the water can be diverted again towards the existing pipe.

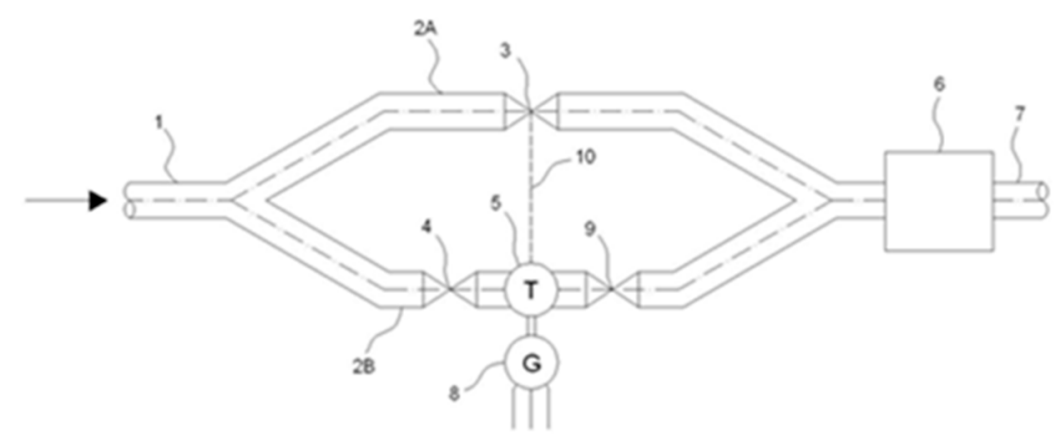

Figure 2. Device Scheme.

The developed device can be installed in parallel to the existing facilities, taking advantage of most of the infrastructure and thus minimizing the cost of the associated work. On the other hand, the existence of an alternative pipe makes it possible to ensure the reliability of the supply, which is of vital importance in drinking water supply networks. Besides, it allows to have a other 
additional tool for the control of the overpressures in case of sudden closings or incidents in the turbine, since it is possible to divert the flow or part of it if is necessary.

These types of facilities are usually located in sites with complicated orography, where the available space and the access are usually not optimal. For this reason, the product was designed as a modular device and built in factory. In this way, the activities on the ground are minimized, the installation times and costs are reduced, as well as the intervention in water conduction. On the other hand, the ecological impact is minimized. To reduce the carbon footprint of the installation, the modular device is carried out at a single time and the civil works are being reduced only to the bypass pipes and the foundation needed for the structure.

\section{Project Objectives}

The main objective of the project is focused on producing "green electricity", contributing with that to the fulfillment of the European Commission's agreements regarding the increased use of renewable energy sources, thereby helping to reduce greenhouse gas emissions and therefore the compliance with the Kyoto protocol and with the Renewable Energy Plan of the Spanish Government (PER 2011-2020) which set the target to achieve $268 \mathrm{MW}$ in installations with less than $1 \mathrm{MW}$.

To achieve this general goal, it will be necessary to establish the individual objectives shown below:

- Using kinetic and potential energy currently wasted in distributions and water supplies networks.

- Generating "green electricity" for use in urban and/or industrial areas.

- Contributing to reducing the carbon footprint.

- Demonstrating technical and economic feasibility of the modular power generator through the manufacture of a pilot plant built in factory and transported to integrally mount on the particular site for this purpose.

- Releasing project results to the greater public and scientific community as possible, paying particular attention to the Governments for being them more so, the owners and donors of concessions on the use of potable water networks.

- Promoting new public policies for energy saving and sustainable mobility based on the economic benefits of the pilot plant.

- Demonstrating reduction of the environmental impact of the proposed solution comparing to traditional small hydro installed in situ.

- Contributing to simplify and reduce administrative barriers to these systems, favoring this way its generalization.

\section{Results}

The main results related to this project are:

- Modular power generator in a pilot plant scale. Development of hydraulic co-generation pilot plant in water abduction and distribution network using a pressure reduction system that runs in parallel to the load-break boxes provided with sealing disc or the like, in which the reduction of pressure is performed by hydraulic turbine obtaining, together with an electric generator, a remnant energy.

- Generation of 700,000 KWh of electricity from the kinetic and potential energy of the water that arrives to the rupture zone of Villandio, Mieres.

- Contributing to reduce GHG emissions.

- Development of the project's Website in order to broadcast the essential information about the environmental performance of the project.

The pilot plant is installed nearby the Herradura reservoir, in Mieres, Spain. The main characteristics of the installation place and the pipe network had conditioned the design. In Figure 3 
is shown the general implantation drawn, and in Figures 4 and 5 some images of the device are shown. Some videos are available as Supplementary Materials.

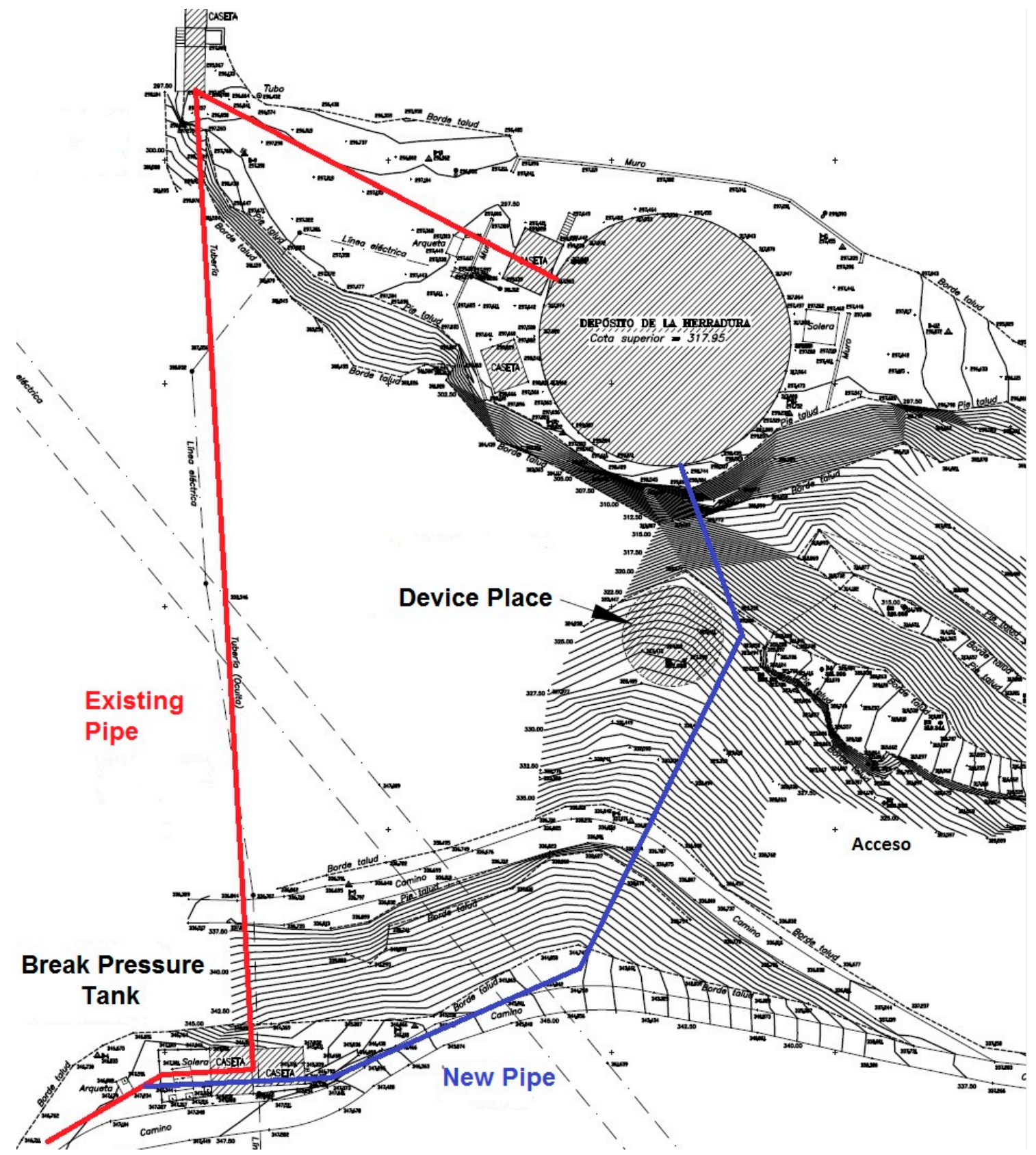

Figure 3. General Implantation.

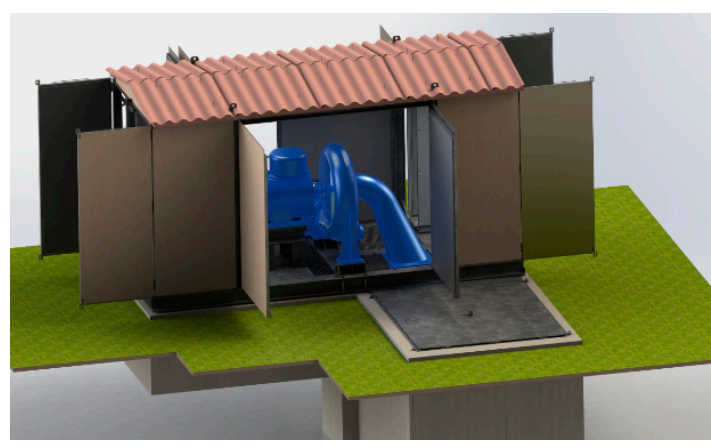

(a)

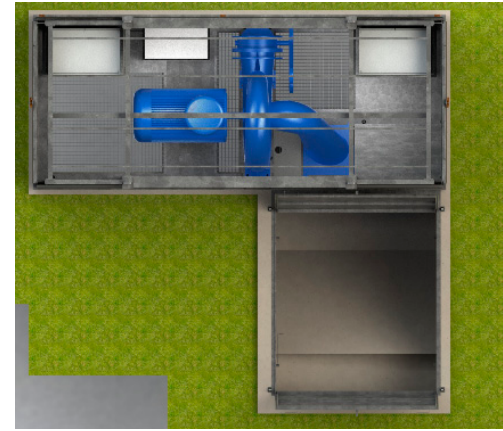

(b)

Figure 4. Designed device: (a) Turbine module; (b) Top view of the module. 


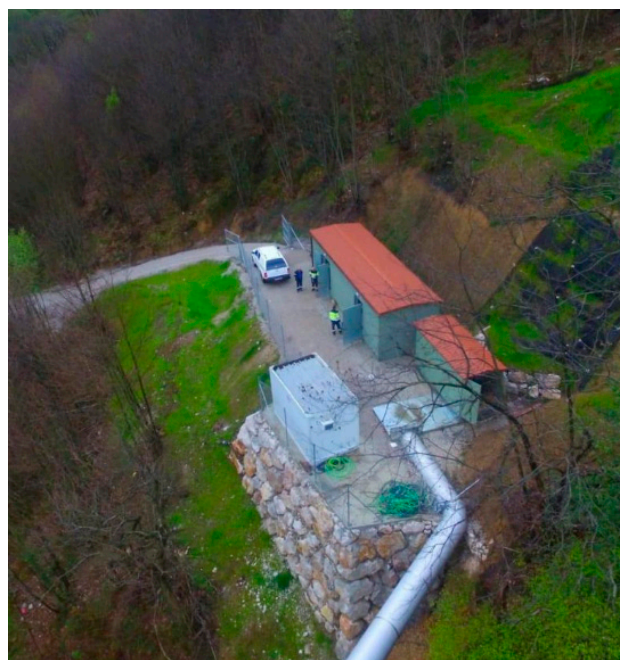

(a)

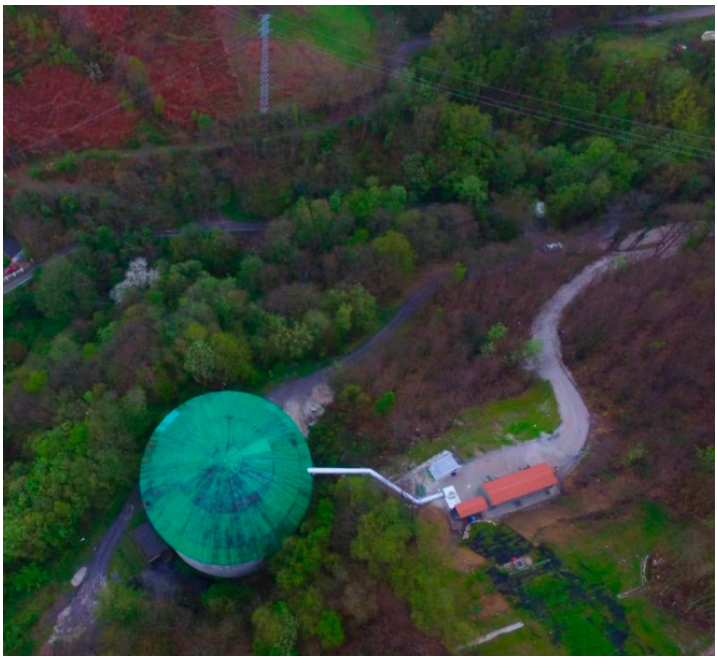

(b)

Figure 5. Aerial View: (a) Turbine module and electrical building; (b) The device and the final reservoir.

Supplementary Materials: Videos and other interesting information about the project are available online at http://www.lifehygenet.eu.

Author Contributions: D.Á.D. and S.G.M. develop and calculate the turbine module. M.A.F.H. coordinate all the project and all the works of the different partners involve.

Acknowledgments: All the works collected have been made in Prodintec and this work has been supported by Life+ Program (agreement code: LIFE12 ENV/ES/000695). The authors also acknowledge all the activities developed by the members of the consortium project (INGEMAS, ServoShip, FAEN and Ayuntamiento de Mieres).

Conflicts of Interest: The authors declare no conflict of interest. The founding sponsors had no role in the design of the study; in the collection, analyses, or interpretation of data; in the writing of the manuscript, and in the decision to publish the results.

(C) 2018 by the authors. Licensee MDPI, Basel, Switzerland. This article is an open access article distributed under the terms and conditions of the Creative Commons Attribution (CC BY) license (http://creativecommons.org/licenses/by/4.0/). 